\title{
Understanding volcanic impacts through time
}

\author{
Celine Vidal', M. Toohey ${ }^{2}$, M. Sigl ${ }^{3}$, K. Anchukaitis ${ }^{4}$, F. Ludlow ${ }^{5}$ and A. LeGrande ${ }^{6}$
}

\section{4th VICS workshop, Cambridge, UK, 13-16 April 2019}

The Volcanic Impacts on Climate and Society (VICS; pastglobalchanges.org/vics) working group initiated Phase 2 this year. The aim of Phase 2 is to extend the scope of VICS to major eruptions throughout the Holocene and beyond by exploring evidence of volcanic forcing, testing model experiments, and placing an increased emphasis on archaeological evidence of societal impacts and responses to complement the focus on written records from Phase 1. This year, the meeting - the largest to date - gathered 70 delegates with expertise in history, archaeology, dendrochronology, ice cores, climate modeling, tephrochronology, and volcanology.

\section{Eruptions of the Common Era}

The integration of historical records continues to improve our understanding of the physical processes that occurred during past volcanic eruptions and their links with societal hardships, such as the 1783 Laki (Iceland) or 1257 Samalas (Indonesia) eruptions. The exegesis of historical records can help establish links between severe volcanically induced climate deterioration and major societal stressors such as famines and/or epidemics, which may in some cases promote large-scale societal reorganizations (e.g. Manning et al. 2017). Presenters demonstrated a growing recognition that the repeated occurrence of volcanic climatic "shocks", increasingly clear in paleoclimatic records, now provides historians and archaeologists with an important diagnostic tool to chart the evolution of societal vulnerabilities to sudden environmental change.

Presenters highlighted advances in satellite observations of volcanic aerosol, detection of volcanic signals in ice cores, and the use of idealized and comprehensive aerosol models. While uncertainties in aerosol reconstructions will always be present, current efforts are helping to constrain volcanic forcing estimates. For example, analysis of the isotopic composition of ice-core sulfate can be linked to injection height, which has a large impact on the reconstructed radiative forcing (Burke et al. 2019). Advances in dendrochronological records were presented, including work investigating the sources of differences between hemispheric reconstructions, and work looking at the impact of volcanic eruptions on large-scale temperature gradients and their potential impacts. A perspective from the Southern Hemisphere argued that large eruptions in the instrumental era have consistently led to cold temperatures in South Africa.

New evidence was presented on the search for the eruptions responsible for the frequently studied sulfate peaks in ice cores in 536 and $540 \mathrm{CE}$ and major cooling suggested by tree rings in the mid-sixth century, marking the onset of what has been termed the Late Antique Little Ice Age (Büntgen et al. 2016). This cold period coincides with major societal reorganizations in Eurasia and Central America (Fig. 1). Source candidates such as Ilopango volcano (El Salvador) and El Chichón (Mexico) were suggested (Nooren et al. 2017) with new age estimates leading to different conclusions. This highlights the challenge and importance of accurate dating when identifying eruptions and their potential impacts.

\section{Pre-Common Era eruptions}

Beyond the Common Era, tree rings show some strong volcanic cooling events throughout the Holocene (e.g. in the fourth and seventh millennia BCE, Nicolussi et al. 2009). Climate modeling suggests that the seventh millennium BCE Mt. Mazama eruption (USA) would have triggered strong cooling in the Northern Hemisphere (Krüger et al. 2018).

Further in the past, archaeological studies are key to understanding the impact of large events, such as the Laacher See eruption (Germany) 13,000 years ago, which had profound effects on the way of life of local contemporaneous Final Paleolithic foragers

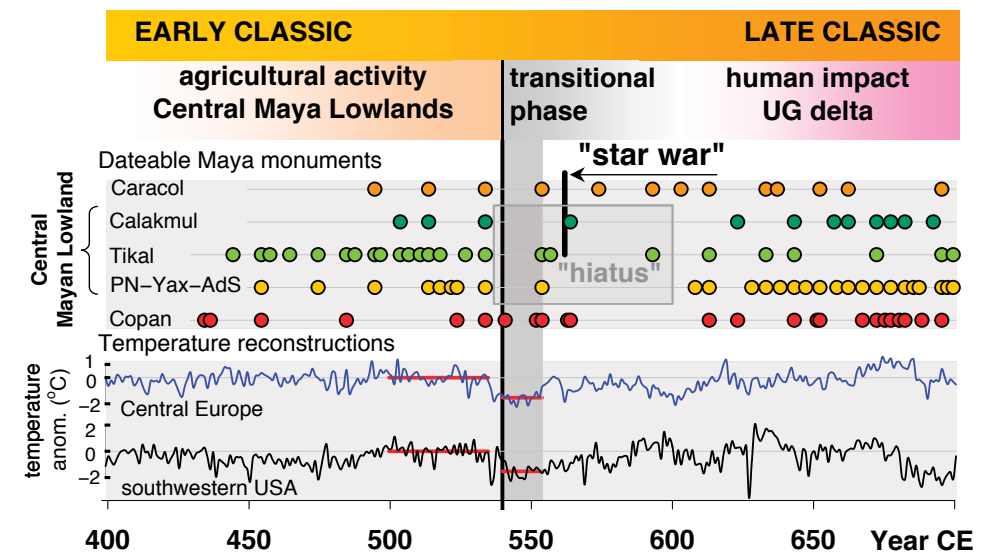

Figure 1: Late Antique Little Ice Age and transformations in the Mayan culture and Northern Hemispheric summer cooling (modified from Nooren et al. 2017 and references therein). Key: PN: Piedras Negras; Yax: Yaxchilan; Ad S: Altar de Sacrificios.
(Riede 2017). Tephrochronological studies in Eastern Africa are helping to constrain the impact of explosive volcanism on our hominid ancestors in the Pleistocene. In the Ethiopian rift valley, a dozen major eruptions between 360,000 and 100,000 years ago drastically remodeled landscapes and ecosystems, and potentially isolated populations in regions of the rift (Vidal et al. unpublished data).

\section{Outlook}

Interdisciplinary groups defined during the second VICS workshop (Zaragoza, Spain, May 2017) are currently working on case studies of eruptions of the Common Era and the first two centuries BCE. It is planned that the outcome of these study groups will take the form of a special issue in Climate of the Past to be published in 2020. Another future focus for $\mathrm{VICS}$ will be the investigation of the impact of volcanic halogen on the ozone layer and possible records and proxies of ozone depletion, a process that has recently attracted high interest (e.g. McConnell et al. 2017).

The interdisciplinary nature of research on volcanic impacts is a great strength, but can also pose a challenge for those new to the topic. The VICS community identified the potential value of a "best practices" document, including recommendations for each area of expertise, which would aim to give background on the most important methods, data sets, and assumptions that underpin VICS' research efforts.

\section{ACKNOWLEDGEMENTS}

Thanks to PAGES, QRA, the Department of Geography (Uni. Cambridge) and the Cambridge TephraLab.

\section{AFFILIATIONS}

'Department of Geography, University of Cambridge, UK ${ }^{2}$ GEOMAR Helmholtz Centre for Ocean Research, Kiel, Germany

${ }^{3}$ Climate and Environmental Physics, University of Bern Switzerland

${ }^{4}$ School of Geography and Development and Laboratory of Tree-Ring Research, University of Arizona, Tucson, USA ${ }^{5}$ Trinity Centre for Environmental Humanities, and Department of History, Trinity College Dublin, University of Dublin, Ireland

${ }^{6}$ NASA Goddard Institute for Space Studies, New York, USA CONTACT

Celine Vidal: cv325@cam.ac.uk

\section{REFERENCES}

Büntgen U et al. (2016) Nat Geosci 9: 231-236

Burke A et al. (2019) Earth Planet Sci Lett 521: 113-119

Krüger K et al. (2018) EGU Conf Abs 20: 12097

Manning JG et al. (2017) Nat Commun 8: 900

McConnell JR et al. (2017) Proc Natl Acad Sci 114 10035-10040

Nicolussi Ket al. (2009) The Holocene 19(6), 909-920 Nooren Ket al. (2017) Geology 45: 175-178 Riede F (2017) Splendid Isolation, Aarhus Universitetsforlag, $214 \mathrm{pp}$ 